\title{
Palabras escritas al margen de la sociedad
}

\author{
Palabras claves: poesía mapuche, David Aniñir Guilitraro, poesía y \\ política, palabra poética, neologismos, nuevo lenguaje poético.
}

\section{Introducción}

En el presente trabajo planteo una reflexión sobre el lugar que ocupa la palabra dentro de la poesía, y sobre cuál es su función. Sobre este cimiento luego expongo mis investigaciones acerca de la poesía mapuche ${ }^{1}$ del poeta David Aniñir Guilitraro, su palabra poética y analizo la posibilidad del desarrollo de un posible nuevo lenguaje dentro de la poesía e incluso dentro de la sociedad mapuche. El artículo está escrito a partir de mi tesis de Filología Hispánica titulada Al medio camino de un mundo que se eleva y el libro poético de David Aniñir Guilitraro, Mapurbe venganza a raíz.

1 Los mapuche (mapu: 'tierra' y che: 'gente') son un pueblo indígena que vive en el territorio que hoy en día se denomina Chile y Argentina. El año 1541 marca el inicio de la conquista española de aquel territorio. Los mapuche se rebelaron y lograron establecer una frontera en el río Bío-Bío. En el año 1810 Chile se independizó de la corona española y en su afán de unificar a toda la población que en aquel entonces vivía en la tierra chilena, empezaron en 1861 con la llamada «Pacificación de la Araucanía» (denominación del territorio donde vivía la mayoría de los mapuche). Muchos indígenas fueron exterminados o fueron despojados de sus casas, les prohibieron usar su lengua (el mapudungún) y desenvolverse en su cultura y cosmovisión. Les robaron muchas hectáreas de su tierra y les obligaron a ir a vivir a reducciones. Hasta hoy en día no ha cesado la «pacificación», puesto que muchos mapuche siguen viviendo en la pobreza, sin tierra, experimentando una violencia muy notable ejercida por parte del estado chileno. Como respuesta a esta violencia han crecido y siguen surgiendo organizaciones que luchan por los derechos del pueblo mapuche.

El gentilicio «mapuche» es un sustantivo colectivo y debe utilizarse en singular, debido a que designa un conjunto de elementos de la misma especie. 


\section{Palabra poética y palabra política}

La palabra se entiende y es la base esencial de los fenómenos sociales, no es solo signo lingüístico, sino también y sobre todo signo ideológico. Según la teoría marxista y su estudio del lenguaje y de la palabra, la característica clave de la palabra, el signo lingüístico, es su omnipresencia a través de las relaciones interhumanas. Por ello es la primera manifestación de los cambios sociales, incluyendo los que recién se están creando y están buscando vías para formar parte de algún cuerpo ideológico. Es «el lugar de pegamento» al que se adhieren ciertos fenómenos sociales.

Los formalistas rusos ${ }^{2}$ describen la palabra como «desnuda», una entidad autosuficiente dentro del léxico preestablecido, mecanizado que se impone al poeta sin cederle espacio creativo, autónomo. Asimismo la variedad léxica que suele contener la palabra se explica a modo de dialáctica linguística interna y no de su proyección hacia fuera, a otros planos léxico-ideológicos. Según esta teoría, el contexto donde se sumerge una palabra nunca está fuera sino siempre dentro de un sistema lingüístico. Uno de los formalistas rusos, Viktor Šklovski³ , el que más se dedicó al estudio de la palabra, aspiraba, bajo las pretensiones futuristas, crear un lenguaje poético nuevo, particular. Pavel Medvedev $^{4}$ le reprochó este propósito, así como un concepto de lenguaje poético peculiar según el cual los fenómenos lingüísticos coinciden con los poéticos; si queremos percibir el lenguaje poético como un lenguaje particular, debemos entender este mismo lenguaje como un ente hermético, una estructura fonética, morfológica, sintáctica. Un lenguaje está indudablemente constituido por todo lo recién mencionado, las formas gramaticales, pero definitivamente no es lo único que lo constituye. Un componente indefectible de una palabra es su sentido ideológico; es lo que le confiere libertad al lenguaje, posibilidad de desarrollo y creatividad. El pensamiento formalista es en sí un pensamiento ahistórico, ya que no considera el desarrollo y los cambios en la base material de la sociedad y tampoco en su supraestructura.

2 Los estudios sobre poesía en la teoría formalista rusa abarcan un campo artístico muy amplio. Me apoyo sobre todo en las investigaciones de Viktor Šklovski donde se dedica al estudio de la palabra. Sus reflexiones son resumidas a partir de dos artículos: «Vstajenje besede» $\mathrm{y}$ «Umetnost kot postopek» (en Bajt, 1984).

3 Šklovski comprende el arte como «exterior»e «interior» y deja el «significado» de lado. Reduce la forma «exterior» a «sonido/voz» y no relaciona la «interior» con el «significado» (en Bajt, 1984: 422).

4 Medvedev es uno de los críticos del formalismo ruso (V. N. Vološinov y M. M. Bahtin). Medvedev y Vološinov eran los discípulos de Bahtin y muchos trabajos que hoy en día se conocen bajo la autoría de Medvedev y Vološinov, son los estudios de Bahtin. 
Mihail Bahtin y Valentin Vološinov (1929), dos críticos del formalismo ruso, en su libro Marksizmi in jezikoslovje rechazan tanto la teoría del «objetivismo abstracto» como la del «subjetivismo individualista». La base de su crítica está en el signo lingüístico -la palabra- el fenómeno ideológico par excellence. Según Bahtin no existe nada en lo individual que no existiera también dentro de lo social, el intercambio personal, el material de las palabras. «Cada signo se cimenta a través del proceso de interacción entre las personas socialmente organizadas y es por esto que no lo debemos aislar de los variados tratos sociales; fuera de ellos se volvería una simple entidad física» (Bahtin/Vološinov, 2005: 27). Para que un objeto se transforme en un signo lingüístico, debe contar con el apoyo del grupo socioeconómico, otorgándole validez. Una palabra se va formando entre (mínimo) dos interlocutores, es la puente entre un emisor y un receptor y es el lugar de creación a base del punto de vista del otro, de la colectividad; el signo lingüístico se convierte de esta forma en un signo ideológico.

M. Bahtin (1982) escribe acerca de la palabra en la poesía y explica que cada palabra cuenta con un objeto al cual se dirige; el objeto está cercado de pensamientos, puntos de vista, juicios y la palabra que apunta a tal objeto se vuelve discursiva. «Una palabra es como un rayo quebrándose en su camino hacia su objeto, un campo repleto de palabras foráneas, juicios e intereses que sobrepasa el rayo»5 (Bahtin, 1982: 58). Según el mismo autor la poesía es el arte lingüístico y el poeta puede y debe crear únicamente dentro de un leguaje herméticamente sellado. Este lenguaje se refiere a su fracción sintáctica, estilística, mientras que el contenido no posee mucha importancia. Por otro lado el investigador rehúsa el concepto de la posibilidad de un lenguaje poético particular puesto que del mismo modo que lo hace la conciencia de un poeta, el lenguaje nunca logra ser una entidad homogénea. Para obtener esto, el lenguaje debería enajenarse de todas las palabras, juicios y acentos que lo van sosteniendo y creando una multitud de universos, formas ideológico - discursivas. Un lenguaje poético particular puede coexistir en un tiempo y espacio regido por una ideología y lenguaje aglutinados. Este prototipo del lenguaje suele ser manejado como instrumento de dictadores para instaurar unanimidad en otros campos (fuera del signo) de formación social ideológica.

Según la teoría marxista el arte es el reflejo de la realidad objetiva, se entiende bajo el concepto de la «forma ideológica» que se ajusta a una infraestructura de fuerzas productivas levantadas y modificadas a lo largo de la historia. Si esto

5 Todas las traducciones del esloveno al español en este artículo son de la autora si no se indica de otra manera. 
fuera cierto, el arte representaría un objeto de forma objetiva, real. Puesto que el signo es el reflejo de una realidad fraccionada, la relación del arte a la realidad objetiva que atañe no puede ni tiene que ser la relación hacia un «objeto» que el arte quiere representar. Lo que tanto poesía como arte se proponen es apresar el material ideológico ya fraccionado anteriormente, fraccionarlo nuevamente y de esta manera contribuir al desarrollo de esta contradicción. Según el sociólogo esloveno Rastko Močnik (2007: 49-81) lo recién explicado es un procedimiento poético vanguardista que logra permanecer como tal sin convertirse en mercancía dentro de la sociedad capitalista únicamente si persiste como excomulgado del esquema social contemporáneo y a la vez explora nueva(s) localidad(es) donde poder ubicarse y ubicar a la comunidad, o sociedad. Para que el arte procese de manera secundaria un signo que ya ha sido fracturado anteriormente (la segunda o tercera fracturación), necesita hallarse fuera de la formación ideológica que necesariamente envuelve el aparato político-ideológico del estado.

En las sociedades modernas presenciamos un acrecentamiento de las prácticas artísticas, su «mercantilización» y su desplazamiento a la esfera política. Si una práctica desea no perder su estatus de animar y hacer evolucionar a personas y sociedades, debe autoexcomulgarse del aparato político del estado; de lo contrario corre riesgo de adaptación y despolitización. Para que el arte y la poesía persuada, despierte y provoque un cambio, debe hacerse política. El arte verbal es el primero en lograr esto, puesto que su atributo, la palabra tiene la capacidad de alcanzar los más estrechos poros sociales y despojar de allí a la vieja formación política. El historiador del arte y poeta esloveno Miklavž Komelj (2009) escribe dos textos: Političnost poezije y $V$ čem je političnost partizanske umetnosti? y emprende con una tesis de la «inconmensurabilidad» ${ }^{6}$, incompatibilidad e incomparabilidad de poesía y política. Para que la poesía mantenga su soberanía, debe alejarse y abstenerse de todo lo político. Cuando el arte permanece y crea dentro de la formación ideológica, se está subyugando a esta misma formación; termina siendo sólo una parte de ella, puesto que no la problematiza, sino la estetiza, metaforiza y ofrece unas enunciaciones que no reflejan la realidad y tienen como resultado una poesía despolitizada. Para que la poesía se haga política, necesita romper con la formación política e ideológica oficial. La vanguardia logra hacerlo no distanciándose de ella, sino interviniendo en ella. Komelj sostiene que la palabra poética debe ser revelada como impensable e inviable; es la única manera de rebelarse contra esta inviabilidad

6 La inconmensurabilidad es un concepto filosófico según cual existe una imposibilidad de comparación de dos teorías cuando no se cuenta con un lenguaje teórico común. 
y la única forma de engendrar un discurso verdaderamente político puesto que una poesía política no es aquella que consume el material ideológico de la esfera estatal, sino aquella que se basa en los procedimientos poéticos que problematizan la esfera artística autónoma y siguen con la política y las formaciones ideológicas. «La inviabilidad de nuestras vidas a lo político puede mostrarse intensamente política» (Komelj, 2006: 92). La continuación de este artículo se centra sobre lo político en la poesía del poeta mapuche David Aniñir Guilitraro, «que no revive el canto de sus antepasados (como la mayoría de los poetas mapuche); más bien nos muestra a un sujeto mapuche que incorpora problemáticamente toda aquella tradición» (Barros Cruz, 2007).

\section{La poesía del poeta mapuche David Aniñir Guilitraro}

David Aniñir Guilitraro «nació en la mierdópolis sanitiaguina el 29 de agosto. Reside en la comuna de Cerro Navia. Sus primeros escritos fueron las cartas que redactaba a su madre por su necesidad de conectarse con los parientes de su tierra sureña» (Sacamuelas y Mezewey, 2011). En 2005 fue publicado su poemario Mapurbe venganza a raíz, un texto innovador que es al mismo tiempo su programa estético-poético; «Mapurbe» es la «concepción de identidad mapuche urbana que se ha adscrito al patrimonio cultural mapuche contemporáneo». Sus poemas representan a hombres y mujeres que no ven ni pisan nunca su madre tierra, porque «Somos mapuche de hormigón / Debajo del asfalto duerme nuestra madre / [...]» (Aniñir, 2005: 33). Sus mapuchemas no se refieren al imaginario mapuche tradicional, porque él «vive en una población y tiene un historial detrás, se reconoce mapuche en las circunstancias dadas: no quiere una $\mathrm{ruka}^{7}$, vive en la ciudad y frente a eso va a dar pie» (Sacamuelas y Mezewey, 2011). Este es el imaginario de donde salen todos los personajes que protagonizan sus poemas, son como la pequeña esperanza que se puede tener y la proyección de la lucha que está en el inconsciente colectivo de los mapuche y de los no mapuche. La condición mapuche es el lugar desde donde se instala, pero quiere abordar la injusticia desde una perspectiva completa.

Hago mi poesía desde una realidad mapuche urbana poblacional, marginalidad que busca no marginarse; mi propuesta es una poesía más cruda que no tiene nada de aquellos (de los esencialmente mapuche que viven en las comunidades rurales), pero sí evoca ese rasguñar entre el asfalto, para pasar un poquito más allá del asfalto y llegar

7 Término que designa la casa tradicional mapuche. 
a donde están ellos (los poetas emblemáticos mapuche, Elicura Chihuailaf, Leonel Lienlaf y Jaime Luis Huenún). Rompiendo un poco con esta ola de materialismo con lo espiritual. (Sacamuelas y Mezewey, 2011)

El poeta inaugura su poemario con la siguiente estrofa; «Mapurbe / Eres tú / Que se mira / En el espejo / Del tiempo / [...]» (Aniñir, 2005: 4). De estos versos reluce la inconmensurabilidad explicada de antemano. Mapurbe, una noción que no cuenta con su equivalente en la realidad discursiva e ideológica nacional, es inexistente. El espacio ciudadano se ha vuelto el eje crucial de la poética aniñírica, una poética que establece un vínculo con el espacio que habita y se sumerge en las vivencias urbanas para ofrecernos una narración diferente. Lo nuevo de estas escrituras quizás no sean tanto las temáticas que aborda el poeta, sino el lugar de enunciación, totalmente nuevo y preñado de la concepción que queda por construir y gira en torno a qué es ser mapuche hoy. El lector se ve enfrentado a un neologismo fraguado de la palabra mapu, tierra y urbe, ciudad, una contradicción de lo natural y lo artificial que el poeta fusiona y establece así una tensión; la palabra que no existe en el lenguajenorma tampoco puede gestar conceptos. La tensión se resuelve a través de la palabra poética, la poesía refleja y pronuncia la imagen en el espejo de la sociedad. Mapurbe es un levantamiento «en contra de la ciudad, proyecto nación que pretende homogeneizar y unificar las identidades mediante un discurso hegemónico e higiénico que pretende anular a todos los sujetos que ponen en riesgo el afán de progreso» y es a la vez un espacio literario-político-utópico que posiciona una cultura-civilización-nación globalizada que ya «no implica el aniquilamiento de otras manifestaciones culturales, las cohabita y se alimenta de ellas» (Barros Cruz, 2009: 32). Los mapuche urbanos, los neomapuche residen en un lugar que se encuentra fuera del mundo: tanto mapuche como occidental, es un espacio limítrofe, intersticial.

Cuando se le niega la existencia a una palabra se le niega también a una cultura; situar la no-palabra al inicio del poemario es a la vez el levantamiento en contra de la opresión y un abrir camino hacia una realidad posible, donde el neologismo tenga un significado y forme parte de una realidad diferente. La continuación del verso está dirigida a la individualidad de cada uno de los lectores y no a la sociedad como conglomerado; el poeta nos invita a cada uno de los que nos acercamos a su poesía a caminar hacia un lugar hoy inexistente e ilusorio, para mirarnos en el espejo del tiempo (¿quién es el que se está mirando?) y contemplarnos, cada uno su cara («Mapurbe eres tú»). Si al mirarnos 
en el espejo percibimos el lugar de la palabra que no existe en nuestra realidad, podemos ver hacia el futuro, evadirnos del sistema cultural -económico- político de nuestra formación social y a través del espejo del tiempo-poesía contemplar y engendrar una nueva objetividad y tiempo. El mismo poeta habla de Mapurbe y dice que es «la respuesta al racismo y a la negación actuales. Es una poética de la venganza» (Wadi, 2011). Una venganza verbal.

En la estrofa tomada del poema Temporada apológica, el poeta nos confronta con la imposibilidad de su lenguaje dentro del lenguaje-norma; «Mis mapuchemas no entienden nada / Extienden el descontento de los muertos / Y su futura compañía / Mis mapuchemas son elásticos quemados / Cenizas / Rimas de vientos ancestrales» (Aniñir, 2005: 9). Si observamos la estrofa en su totalidad vemos un oxímoron, ya que se excluyen ideas que en la realidad cotidiana son inseparables. Lo primero que se observa es de nuevo un neologismo (mapuchemas), que no existe en el lenguaje-norma y con el procedimiento de apartamiento influye en el lector, le muestra que sus poemas no entienden porque son parte de alguien que está excluido de una esfera donde sí contaría con la posibilidad de comprender. Con el simple empleo de esta palabra el poeta desplaza el poema completo de todo lo ajustado y le engendra un espacio en el no-espacio, en su oposición, allí donde no entiende. Estamos parados frente una poesía que no trata de disimular la imposibilidad de hablar, sino que se atreve a revelarla y de esta manera propiciarla. Una pregunta adecuada sería: ¿es posible que el poeta no entienda a su poesía, no se entienda? No. A lo que sí aspira el autor es a trasladar al lector a una realidad paralela, donde la misma poesía no entiende; no porque no exista (con el pronombre personal mis se adueña del poema y los poemas), sino porque no encuentra el contacto con lo autónomo, lo que a la vez niega y no deja respirar a los mapuchemas. La existencia del poema está en su no-existencia, que es al mismo tiempo el lugar donde el poema ya existe; en la primera estrofa leemos la palabra cenizas, elásticos quemados, donde todavía hay vida, rimas, versos ancestrales que los preservaron los vientos ancestrales y pudieron llegar así hacia sus mapuchemas. La crítica por no entender no está dirigida al exterior, sino precisamente al interior; él es el que no entiende y busca el apoyo entre los que ya no están. «[...] / Mis tristemas se fecundan en el vientre / De la madre más puta / [...] (ibid.); no justifica a los muertos, sino los inculpa por la inexistencia de los mapuchemas que dejaron de existir porque ellos los dejaron de cantar; Aniñir deja su poema sin voz, sin intelecto, la mata para poder fundar de su víctima algo nuevo. 
Mapuchemas, tristemas, mapurbe, mapunky, mapulinda, mierdópolis, flaitedungun son solo algunos de los neologismos aniñíricos. María José Barros Cruz alude en su artículo a Lord Carter, quien sostiene el gesto de usar neologismos «como un mecanismo desestabilizador de la hegemonía» o, según Adrian Moyano «como una tensión que expresa la incomodidad del poeta ante el uso de la lengua del dominador» (Barros Cruz, 2007). Un neologismo es siempre un neoconcepto, un repensar de la cultura y el lenguaje, una aspiración de llenar el silencio-vacío del espacio intersticial. Se trata de palabras comprensibles, se entiende muy bien a qué se refiere el poeta, pero el lector no puede ignorar la composición de dos lenguas en una misma palabra o dentro de una noción, lo que lo encamina a la existencia no solamente de una lengua diferente, sino a la posible presencia de un individuo-cultura-lengua hasta ahora tapados, sumergidos en un espacio reservado y escondido delante de la población chileno-global.

«Para romper con el silencio el poeta tiene que testimoniar la inviabilidad del habla y para sobrepasarla debe adoptar la voz que le es extraña. Es el procedimiento que la vuelve arma» (Komelj, 2006: 104). Este procedimiento es la re-memorización, es «valerse del lenguaje-memoria del otro, para revestirse con él y estar de un modo distinto en él. Se trata de releer y refundar un pasado desde el lenguaje del otro que me contiene, subvertir un pasado con una nueva escritura que es inseparable de aquella ya emitida» (Foerster González, 1998: 94). En el poema Salmo 1997 asistimos la composición de una polifonía discursiva donde «cada sujeto contribuye desde su patrón cultural» (Foerster González, 1998: 95). El Padre nuestro, la oración más conocida, también entre los no católicos, está refundada desde el pasado y situada en el año 1997, cuando la empresa ENDESA Chile inicia la construcción de una segunda central hidroeléctrica Ralco en la zona del Alto Bío Bío. Los mapuche-pehuenches que habitan la zona se niegan a abandonar sus tierras. Se inundan miles de hectáreas de tierras y sitios sagrados. Se trata de una forma del diálogo entrecruzado y se establece un verdadero juego verbal intercultural;

Padre nuestro que estás en el suelo / [...] / Hágase señor tu unámine voluntad / Así como lo hacen los fascistas en la tierra / -nuestra tierra- / [...] / Danos hoy nuestro pan que nos quitan día a día / perdona nuestras verdades / Así como nosotros condenamos / A quien no las entiende / No nos dejes caer en esta invasión / Y mas líbranos del explotador / [...] / En el nombre del padre soltero / Del hijo huérfano / And the saint spirit. / (Q.E.P.D.). (Aniñir, 2005: 21) 
A primera vista debería interpretarse como una forma brutal de apoderarse de lo occidental, pero parece ser la única manera de desenmascar el estereotipo negativo que se ha querido y se quiere establecer del mapuche entendido desde el punto de vista de la historia oficial. La realidad que deben habitar diariamente las comunidades mapuche se cuenta a través del lenguaje -cosmovisión cristiana- occidental para «poner de manifiesto que el lenguaje que lo vehiculiza forma parte del lenguaje desde donde se debe hablar para superarlo, en la medida que ese lenguaje se ha hecho carne de mi carne» (Foerster González, 1998: 95). Es a la vez el lenguaje que se apodera del silencio y del vacío, del espacio entre medio; el poema es en sí un espejo de lo que comprende tal espacio: de la violencia que el sistema chileno ejerce sobre las comunidades mapuche, de la pobreza y la tierra enajenada y la invasión que no cede, de toda la maldad que se adueñó de las comunidades a través de la oración hoy releída y refundada como símbolo de un tiempo pasado que sigue dejando sus huellas. El poema, las palabras construyen lazos, ya que el sujeto del poema es a la vez mapuche y buinca ${ }^{8}$, son dos entidades en una, tan apartadas cultural e históricamente pero a la vez tan fusionadas que no queda espacio entre una y otra. Es la hibridación cultural representada a través de los ojos de un mapuche urbano, un neomapuche que no persiste atrapado ni en la mapuchidad ni tampoco en la chilenidad sino se extiende a la esfera global, como una muestra del conflicto mapuche-chileno que debería concernir al mundo en su totalidad y también como una evidencia del saint spirit universal responsable (aunque inmediato) de las injusticias que se han ejecutado y se siguen ejecutando sobre los mapuche.

\section{La creación de un nuevo lenguaje}

Al hablar de la imposibilidad de hablar, entender y existir dentro del espacio político-cultural, la poesía refleja lo que esta misma política estaba y está realizando durante un largo período de tiempo: imposibilita el habla mapudungún y el entendimiento (la exclusión de los jóvenes mapuche de la formación). Reflejando la imposibilidad de una poética estandarizada, es a la vez la invención de un espacio-innovación poética. Sus poemas son cenizas solo para que resuciten como elásticos quemados y vuelvan, no donde deberían entender, sino donde ya entienden, perpetuamente. No se procura crear un espacio. El espacio ya existe. Lo que sí se necesita es su redescubriemiento y para esto hay que levantarse y esforzarse en no entender y crear signos, realidades nuevas. En

8 Huinka o winka significa «extranjero, el no mapuche». 
este punto el poeta vincula la poesía con la política; problematizando la poesía problematiza la política, entreabre la zona donde los mapuchemas se entienden o se entenderán. Es el lugar del encaminamiento y es inubicable, habrá que inventarlo entre todos. Aquí está lo político.

El poeta Aniñir agarra su realidad confusa, el espacio intersticial a través de una institución donde vamos entrando los seres humanos y donde vamos dejando huellas, es donde todo ya está y nada todavía está dicho; es el lenguaje, la palabra que es a la vez la historia y el futuro, el lugar en el que el poeta aspira a penetrar. El poeta es doblemente forastero, por lo que debe enfrentarse a los obstáculos existentes dentro de la sociedad nacional y como miembro de la sociedad indígena, pero sin vivir en el campo, tener un pedazo de tierra que trabajar ni hablar el mapudungún. ¿Quién es él? No tiene casa, «no quiere lo forastero, no conoce lo casero» (Močnik, 2006: 127). ¿ Es un sujeto aculturado?9 José María Arguedas (1950) se rebela contra esta constatación, declarando que él no es un aculturado, sino un mestizo cultural, orgulloso de ser empapado tanto de lo occidental como de lo nativo. El mismo poeta tiene que inventar su realidad, articulando los reclamos de su etnia. ¿Cómo? Adueñándose de la palabra extranjera, superándola y componiendo desde ella un mundo donde él y sus coetáneos se comprendan y puedan vivir. Es un proceso por el que transitó Arguedas cuando deseaba convertir su realidad en un lenguaje artístico. Su meta no se basaba en la «indigenización» del castellano, sino en la modificación del mismo hasta convertirlo en un instrumento propio. Cuenta Arguedas que a través de sus escrituras y su búsqueda de estilo «muchas esencias que sentía como las mejores y legítimas, no se diluían en los términos castellanos construidos en la forma ya conocida y era necesario encontrar los sutiles desordenamientos que harían del castellano el molde justo, el instrumento adecuado» (1950: 64). Para el escritor era «falso y horrendo presentar a los indios hablando en el castellano de los sirvientes quechuas aclimatados en la Capital. Los indios hablan en quechua» (1950: 66). La solución que encontró fue crearles un lenguaje sobre el fundamento de las palabras castellanas incorporadas al quechua y el elemental castellano que alcanzan a saber algunos indios en sus propias aldeas (1950: 66). Si para Arguedas era falso y horrendo presentar a los indios [sic!] hablando en castellano, para Aniñir debe ser igual de falso y horrendo presentar a los mapuche de las ciudades, mestizos hablar en mapudungún (que la mayoría no sabe) o en el castellano literario. Ellos

9 La aculturación es un término definido en el año 1953 en un seminario en la Universidad de Stanford y se define como un «cambio cultural iniciado a partir de la conjunción de dos o más sistemas culturales autónomos y autosuficientes» (Gaete, 1998: 43). 
definitivamente no hablan así. ¿Cómo hablan entonces? Un poeta esloveno, Matija Čop (Močnik, 2006: 128), quiso organizar una inteligencia nacional laica que reformara la sociedad inventando praxis lingüísticas nuevas, que ilustrara el lenguaje, la poesía; también la de Aniñir es una praxis, artística, estética que nace y se forma junto a y en relación con la pluralidad discursiva dentro de una sociedad, los modela y diversifica. A través de los discursos y las palabras (su omnipresencia en la sociedad) crea nuevas prácticas históricas y sociales que vienen del campo artístico y están fuera de lo nacional-político. El poeta va construyendo un lugar de la reconciliación, una posibilidad en el futuro, se dedica y consigue modificar el castellano hasta convertirlo en un instrumento propio. Es un poeta-extranjero, expulsado y si quiere desenvolverse en este espacio debe, paradójicamente, buscar e inventarse fuera, ¿tal vez en el aire? No. Existen un lugar y un sujeto; bicultural y bilengual ${ }^{10}$. El mapuche contemporáneo no siente, piensa y habla en ninguna de las dos lenguas, mapudungún y castellano, sino en las dos a la vez. Es un mestizo que se va apoyando en sus dos idiomas, culturas que lo vieron crecer y lo siguen nutriendo día a día en su empeño de encontrarse a sí mismo y encontrar el camino hacia sus hermanos, tanto mapuche como winka. En este punto nos topamos con la posibilidad de la creación de un lenguaje original que cuenta con la posibilidad de llegar a ser aprobado entre la gente - un espacio que acoja al poeta y a todos los excluidos, los que sí quieren entender y comprender. Las palabras-concepto que Aniñir va concibiendo en su poesía son ejemplos claros de que nos ubicamos ante la posibilidad de crear un nuevo lenguaje que será uno inter y no intrapersonal. Global. No hablo de un espacio y lenguaje aislados e ideológicamente homogéneos. Hablo de un espacio y lenguaje interpersonal donde poder encontrarse. Donde volver. Porque a través de este lenguaje nuevo que aspira a surgir hay un acceso directo a la sabiduría natural que ha sobrevivido a través de los siglos y que en este tiempo, cuando todo parece estar derrumbándose, se levanta de las cenizas. Para renovar y hacer renacer la ética natural, construir una comunidad, una sociedad y humanidad arraigada en su entorno, habrá que abrirse a un lenguaje nuevo-antiguo-natural. ¿YY por qué no a un mapudungún renovado? «La reconstrucción de un lenguaje casi o ya perdido siempre resulta la creación de un nuevo lenguaje» (Casini, 2000: 80). Este va

10 Se trata de un concepto que describe la posición de un sujeto entre dos mundos, dos culturas, el germen de que su mente, su experiencia en el mundo termina siendo bicultural o de bilenguaje. Bilengual no es lo mismo que bilingüe; el segundo concepto nomina una habilidad, el primero nomina un modo de vivir, «una forma de ver el mundo, estar posicionado entre dos idiomas o entre una cultura nacional y una lengua nativa o dentro de un mismo idioma» (Rojas, 2009: 22). 
surgiendo del espacio intersticial donde se originan las relaciones entre pueblos y culturas que «propicien el desarrollo integral de todos y desemboquen en la convivencia armónica y pacífica» (Menchú Tum, 1998: 14). La escritura es una de las grandes tareas al escribir una nueva forma de convivir, de «volver a inventar la esperanza» (ibid.).

\section{Conclusión}

El artículo demuestra que los signos lingüísticos no son entidades herméticamente cerradas, que van cambiando, desarrollándose, expuestos a contactos interhumanos e interculturales. El lenguaje es, justamente por ser parte inseparable de una sociedad, una entidad modificable, tanto en su parte sintáctica como también semática. Puesto que una palabra es una construcción interhumana y suele reflejar la condición de la infra y superestructura sociales, es también un factor de los cambios sociales. Las maneras que emplea el poeta Aniñír a la hora de escribir palabras y componer su poesía, son políticas; rechaza lo oficialmente político, lo denigra y lo pone frente al espejo y de esta forma frente a la sociedad y frente a cada uno de los lectores. De la nada se crea un futuro algo o un futuro todo.

\section{Bibliografía}

Aniñir Guilitraro, D. (2005): Mapurbe venganza a raiz. Santiago de Chile: Producción Editorial.

Arguedas, J. M. (1950): «La lucha por el estilo». En: Arguedas, J. M.: La novela y el problema de la expresión literaria en el Perú. América Nueva, 60-69.

Bajt, D. (izbor) (1984): Ruski formalisti. Izbor teoretičnib besedil. Ljubljana: Mladinska knjiga.

Bahtin, M. (1982): «Beseda v poeziji in beseda v romanu». En: Teorija romana. Ljubljana: Cankarjeva založba, 57-77.

Bahtin, M. y Vološinov, V. (2005): «Marksizem in filozofija jezika. Osnovni problemi sociološke metode v znanosti o jeziku». En: Bahtin M., M./Vološinov V., N, Stalin J., V., Williams, R.: Marksizmi in jezikoslovje. Ljubljana: Društvo za sodobno družbeno politično polemiko-AGREGAT, 21-72.

Barros Cruz, M. J. (2009): «La(s) identidad(es) mapuche(s) desde la ciudad global en mapurbe venganza a raíz de David Añiñir».Revista cbilena de literatura, 75, 29-46. 
Barros Cruz, M. J. (2007): «'Mapuche de hormigón'» extranjeros y expatriados urbanos. La poesía de David Aniñir.» En: www.letras.s5.com/ da1509071.htm.

Casini, S. E. (2000): «Los textos mapuches y la crítica postoccidental» En: Lengua y literatura mapuche. 9, 77-84.

Foerster González, R. (1993): Introducción a la religiosidad mapuche. Santiago de Chile: Editorial Universitaria.

Gaete, T. A. (1998): «Enfoques explicativos de los procesos de aculturación e identidad étnica en ámbitos de interculturalidad y sus proyecciones a la cultura mapuche.» En: Pentukun, 9, 39-58.

Komelj, M. (2009): Kako misliti partizansko umetnost? Ljubljana: cf.

Menchú Tum, R. (enero 1998): «La interculturalidad como utopía.» En: Pentukun, 8, 11-14.

Močnik, R. (2007): Veselje v gledanju. Ljubljana: cf.

Močnik, R. (2006): «Intelektualec in politika». En: Močnik, R.: Julija Primic v slovenski književni vedi. Ljubljana: Založba Sophia, 86-91.

Močnik, R. (2006): «Estetska teorija brez avtonomije». En: Močnik, R.: Julija Primic v slovenski književni vedi. Ljubljana: Založba Sophia, 124-129.

Močnik, R. (2006): «Kultivirati, omikati, izoblikovati jezik». En: Močnik, R.: Julija Primic v slovenski književni vedi. Ljubljana: Založba Sophia, 209-219.

Rojas, R. (2009): La lengua escorada. Santiago de Chile: Pehuén Editores.

Sacamuelas y Mezewey, F. (2011): «NeoLautaro: Entrevista a David Aniñir Guilitraro». En: http://www.animalespoliticos.com/2011/05/06/ neolautaro-entrevista-a-david-aninir-guilitraro/.

Stanič, K. (2014): Al medio camino de un mundo que se eleva. Lectura e interpretación de la poesía de los seis poetas mapuche contemporáneos: Elicura Chibuailaf, Leonel Lienlaf, Graciela Huinao, Rayen Kvyeb, Jaime Huenún y david Aniñir Guilitraro. Tesina no publicada. Ljubljana: FF UL.

Wadi, R. (2011): «'A Poetic Concept of Identity’: An Interview with Mapuche Poet David Aniñir Guilitraro». En: www.upsidedownworld.org/main/ chile-archives-34/3260-a-poetic-concept-of-identity-an-interview-withmapuche poet-david-aninir-guilitraro. 


\section{Katja Stanič}

University of Ljubljana

\section{Words written on the margins of social recognition}

Keywords: Mapuche poetry, David Aniñir Guilitraro, poetry and politics, words in politics, neologisms, new poetic language.

In this article, based on my thesis entitled $A$ medio camino de un mundo que se eleva, I discuss the role of words in poetry, as understood and interpreted by the Russian formalists and later the Marxists. I focus primarily on the parts of their professional literature which deal with the concept of language and the prospects for the creation of a special poetic language. Based on the writings of Slovenian theorists Rastko Močnik and Miklavž Komelj, I discuss avantgarde art and the political aspects of poetry. The core of the article is an analysis of the selected poems of the Mapuche poet David Aniñir Guilitraro; where I discuss his use of words, neologisms and about why and how his poetry is political. I discuss the power of writing, in this case poetry, to (re)create new literary spaces: the domains of encounter, dialogue and culture. In this way, poetry is a political creation. In using words and language, the poet changes them, thus creating new cultural territories. The poet is not acculturated, but he is bi- or multi- cultural; in his poems, he relies on two or more languages, cultures, and thus opens the door to the creation of a new language; not homogeneous and sealed, but heterogeneous and human. This is (should be) at the same time the language of intercultural integration. 


\section{Katja Stanič}

Univerza v Ljubljani

\section{Besede, zapisane na robu družbe}

Ključne besede: mapuška poezija, David Aniñir Guilitraro, poezija in politika, beseda v politiki, neologizmi, nov poetični jezik, akulturacija, bikulturnost

V članku, ki temelji na avtoričinem diplomskem delu, naslovljenem Na pol poti sveta, ki vstaja, je govor o vlogi besede v poeziji, tako kot jo razumejo in razlagajo ruski formalisti in kasneje marksisti. Osredotoča se predvsem na mesta v njihovih strokovnih delih, ki razpravljajo o konceptu jezikovnega znaka in o možnostih za nastanek posebnega pesniškega jezika. Na podlagi zapisov slovenskih teoretikov Rastka Močnika in Miklavža Komelja avtorica piše o avantgardni umetnosti in političnem $\mathrm{v}$ poeziji. $\mathrm{V}$ osrednjem delu članka analizira poezijo mapuškega pesnika Davida Aniñira Guilitrara; na podlagi izbranih verzov piše o besedi v njegovi poeziji, neologizmih ter o tem, zakaj in na kakšen način je njegova poezija politična. Razmišlja o moči pisave, v tem primeru poezije, da (ponovno) ustvarja nova literarna ozemlja - ozemlja srečevanj, dialoga in kulture. Na ta način je poezija politična tvorba. Pesnik s pomočjo besed in jezikov te spreminja in ustvarja nova kulturna ozemlja; ni akulturiran, temveč bi-, poli-kulturen. $\mathrm{V}$ pesmih se pesnik opira na dva ali več jezikov in kultur ter s tem odpira vrata nastajanju novega jezika; ne homogenega in hermetično zaprtega, temveč heterogenega, medčloveškega. To je (bi bil) obenem jezik medkulturnega povezovanja. 